\title{
Changed adipocytokine concentrations in colorectal tumor patients and morbidly obese patients compared to healthy controls
}

Andreas Hillenbrand ${ }^{1 *}$, Juliane Fassler ${ }^{1}$, Nadine Huber ${ }^{1}$, Pengfei $\mathrm{Xu}^{1}$, Doris Henne-Bruns ${ }^{1}$, Markus Templin ${ }^{2}$, Hubert Schrezenmeier ${ }^{3}$, Anna Maria Wolf ${ }^{1}$ and Uwe Knippschild ${ }^{1}$

\begin{abstract}
Background: Obesity has been associated with increased incidence of colorectal cancer. Adipose tissue dysfunction accompanied with alterations in the release of adipocytokines has been proposed to contribute to cancer pathogenesis and progression. The aim of this study was to analyze plasma concentrations of several adipose tissue expressed hormones in colorectal cancer patients (CRC) and morbidly obese (MO) patients and to compare these concentrations to clinicopathological parameters.

Methods: Plasma concentrations of adiponectin, resistin, leptin, active plasminogen activator inhibitor (PAl)-1, monocyte chemotactic protein (MCP)-1, interleukin (IL)-1 alpha, and tumor necrosis factor (TNF)-alpha were determined in 67 patients operated on for CRC (31 rectal cancers, 36 colon cancers), 37 patients operated on for morbid obesity and 60 healthy blood donors (BD).

Results: Compared to $\mathrm{BD}$, leptin concentrations were lowered in $\mathrm{CRC}$ patients whereas those of $\mathrm{MO}$ patients were elevated. Adiponectin concentrations were only lowered in MO patients. Concentrations of MCP-1, PAl-1, and IL-1 alpha were elevated in both CRC and MO patients, while resistin and TNF-alpha were similarly expressed in $\mathrm{MO}$ and $\mathrm{CRC}$ patients compared to BD. Resistin concentrations positively correlated with tumor staging $(p<0.002)$ and grading $(\mathrm{p}=0.015)$ of rectal tumor patients.
\end{abstract}

Conclusions: The results suggest that both $\mathrm{MO}$ and CRC have low-grade inflammation as part of their etiology.

Keywords: Adipokine, Adipocytokine, Cytokine, Colorectal cancer, Morbid obesity, Adiponectin, Leptin, Resistin

\section{Background}

Obesity is an increasing health problem not only for industrialized countries but also for most other parts of the world affecting all ages [1]. Besides the established complications like cardiovascular disorders and type II diabetes mellitus, obesity has not only been associated with a 1.5-3.5-fold increased cancer incidence, but also with increased cancer mortality, especially in morbidly obese patients $\left(\mathrm{BMI}>40 \mathrm{~kg} / \mathrm{m}^{2}\right)[2,3]$. A positive association between obesity and risks for cancers like endometrial or kidney cancer is well documented [4-6]. There is also an association between obesity and colorectal cancer,

\footnotetext{
* Correspondence: Andreas.Hillenbrand@uniklinik-ulm.de 'Department of General and Visceral Surgery, University Hospital of Ulm, Albert-Einstein-Allee 23, 89081, Ulm, Germany

Full list of author information is available at the end of the article
}

however, this association appears to be stronger in males, particularly with visceral adiposity and weaker and less consistent in women, underlining gender-specific differences regarding the correlation of obesity and cancer development [7-10].

A number of mechanisms have been proposed for the adverse effect of obesity on colorectal cancer risk including the distribution of body fat, alteration in hormonal patterns, obesity-related inflammation, and metabolic disturbances [11]. White adipose tissue has been increasingly recognized as an important endocrine organ. The physiological functions of adipose tissue are changed in obesity, leading to an altered secretion of adipocytokines, which may influence cancer pathogenesis and progression $[12,13]$. These adipocytokines, particularly adiponectin, leptin, tumor necrosis factor-alpha (TNF- $\alpha)$, and some

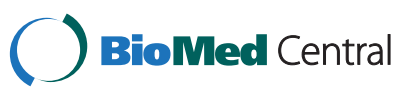


proinflammatory interleukins like interleukin $1 \alpha$ (IL-1 $\alpha)$ [14] may indicate an association between obesity and colorectal cancer by influencing the obesity associated low grade inflammation and the growth and proliferation of tumor stroma and malignant cells within [15-17]. Furthermore, interaction between tumor and stromal cells may influence tumor progression. Tumor associated macrophages, which are major components of stroma and attracted by MCP-1, have been reported to play a role in tumor progression [18].

Knowledge of the pathophysiological mechanisms of these various protein signals underlying the association between obesity and cancer origin may be important for the development of preventive and therapeutic strategies for malignancies. These proteins involved in various signaling pathways are called adipocytokines. Hereafter, the term adipokine refers to the adipose tissue expressed hormones leptin, resistin and adiponectin and the term cytokines refers to IL- $1 \alpha$ and TNF- $\alpha$. Monocyte chemotactic protein-1 (MCP-1) is a chemokine, a protein that acts as a chemical messenger, and active PAI-1 belongs to the family of serine protease inhibitors. In literature there are contradictory reports regarding adipokine concentrations in colorectal cancer patients [19]. Furthermore, recent studies suggest that changes in the expression of adipose tissue expressed hormones may reflect a mechanism linking obesity to tumor genesis [20,21].

The aim of this study is, (i) to provide an adipokine profile in three different groups (colorectal cancer patients, morbidly obese patients and healthy blood donors), (ii) to assess the influence of altered adipocytokine expression on tumorigenesis, (iii) to investigate the association between plasma adipokine concentrations and clinicopathological characteristics of CRC and (iv) to demonstrate similarities in the cytokine/chemokine profile of CRC and MO patients. Our data indicate that $\mathrm{MO}$ and $\mathrm{CRC}$ have both chronic low-grade inflammation as part of their etiology.

\section{Methods}

\section{Patients}

The patients were divided into three subgroups: Subgroup 1: patients with colorectal cancer (CRC); subgroup 2: morbidly obese (MO) patients; subgroup 3: healthy blood donors (BD) as control group. Inclusion criteria to participate voluntarily in the study were age $>18$ years, no further malignant or rapidly progressing or hematologic underlying disease, no HIV/AIDS, or cytotoxic therapy given within the previous 6 months. The study was performed with the permission of the independent local ethics committee of the University of Ulm (approvals 112/2003 and 73/2009). An informed consent of all MO and CRC patients was obtained prior to surgery in the author's hospital.
Fasting blood samples from CRC and MO patients were collected preoperatively at 7 AM. Samples from BD were taken at various times in a non-fasting state $(10 \mathrm{ml}$ venous blood, collected in a chilled syringe with EDTA). All samples were frozen in liquid nitrogen and stored in the tissue bank of the Department of General and Visceral Surgery of the University Hospital of Ulm, Germany.

\section{Cytokine and adipocyte expressed hormone measurement and reagents}

Multiplex analysis kits for IL- $1 \alpha$, TNF- $\alpha$ and Linco-Kit human serum adipokine (panel A, panel B) for MCP-1, active PAI-1, leptin, resistin and adiponectin were obtained from Millipore, Hamburg, Germany. In brief, the appropriate cytokine standards and samples, diluted in plasma dilution buffer, were added to wells of a filtered plate. The samples were incubated with $50 \mu \mathrm{l}$ of the antibodycoupled microsphere set on a plate shaker in the dark at room temperature for $30 \mathrm{~min}$. The samples were washed three times with $100 \mu \mathrm{l}$ wash buffer. Freshly diluted secondary detection antibody $(25 \mu \mathrm{l} /$ well $)$ was added to the wells and then incubated on a plate shaker in the dark at room temperature. Thereafter, samples were washed three times with $100 \mu \mathrm{l}$ wash buffer. Fifty microliters of strepavidin-PE $(16 \mu \mathrm{g} / \mathrm{ml}$ in assay buffer) was added to each well, and incubation continued on a plate shaker at room temperature for the first $10 \mathrm{~min}$. Unbound analytes were filtered through the wells using the vacuum manifold. The bound beads were washed three times with $100 \mu \mathrm{l}$ wash buffer. After the last wash step, $125 \mu \mathrm{l}$ of assay buffer was added to each well and the plate was placed on a plate shaker set at $500 \mathrm{rpm}$ (G-force: $0.84 \mathrm{~g}$ ) for $1 \mathrm{~min}$ and then for $3 \mathrm{~min}$ at a reduced speed of $300 \mathrm{rpm}$ (G-force: $0.30 \mathrm{~g}$ ). Finally, samples were analyzed on the Luminex system in accordance with the manufacturer's instruction at the NMI of the University of Tübingen. The lowest traceable value is according to the sensitivity of the method $0.3 \mathrm{ng} / \mathrm{ml}$ for leptin and $9.2 \mathrm{pg} /$ $\mathrm{ml}$ for IL-1 $\alpha$. Intra-assay precision (Intra-CV\%) and interassay precision (Inter-CV\%) are provided in Table 1.

\section{Statistical analysis}

All values were expressed as median with range. Statistical analysis was performed using WinSTAT software (Version 2009.1; R. FitchSoftware). Data were statistically analyzed using the Mann-Whitney tests, and correlations between the different adipocytokines by the non-parametic Spearman's correlation test. The correlation coefficient is indicated by r. Statistical significance was declared at $\mathrm{p}<0.05$ and a tendency at $0.05<\mathrm{p}<0.10$. No adjustments were made for multiple statistical comparisons. 
Table 1 Median and range of adiponectin, resistin, leptin, active PAI-1, MCP-1, IL-1a and TNF-a plasma concentrations of patients operated on for colorectal carcinoma (CRC) and morbid obesity (MO) as well as healthy blood donors (BD)

\begin{tabular}{|c|c|c|c|c|c|c|}
\hline Parameters Intra-CV\% Inter-CV\% & CRC $(n=67)$ & MO $(n=37)$ & $B D(n=60)$ & CRC vs. BD & MO vs. BD & CRC vs. MO \\
\hline Adiponectin $(\mu \mathrm{g} / \mathrm{ml})$ & 17.1 & $\downarrow 9.4$ & 14.7 & n.s. & $p<0.001$ & $p<0.001$ \\
\hline $3.9 / 7.8$ & $(4.3-51.0)$ & $(3.8-57.8)$ & $(5.7-54.0)$ & & & \\
\hline \multirow[t]{2}{*}{ Adiponectin females $(\mu \mathrm{g} / \mathrm{ml})$} & 21.9 & $\downarrow 12.4$ & 22.5 & n.s. & $\mathrm{p}<0.001$ & $p=0.002$ \\
\hline & $(7.0-40.5)$ & $(5.3-57.8)$ & $(9.8-54.0)$ & & & \\
\hline \multirow[t]{2}{*}{ Adiponectin males $(\mu \mathrm{g} / \mathrm{ml})$} & 14.2 & $\downarrow 8.3$ & 11.8 & n.s. & $p=0.001$ & $p<0.001$ \\
\hline & $(4.3-51.0)$ & $(3.8-12.3)$ & $(5.7-30.7)$ & & & \\
\hline Leptin (ng/ml) & $\downarrow 2.6$ & $\uparrow 45.0$ & 10.9 & $p<0.001$ & $p<0.001$ & $p<0.001$ \\
\hline $6.4 / 9.6$ & $(0.3-33.3)$ & $(1.7-97.5)$ & $(0.3-58.5)$ & & & \\
\hline \multirow[t]{2}{*}{ Leptin females } & $\downarrow 6.7$ & $\uparrow 47.3$ & 15.8 & $p=0.011$ & $p<0.001$ & $p<0.001$ \\
\hline & $(0.3-33.3)$ & $(16.1-97.5)$ & $(0.7-58.5)$ & & & \\
\hline \multirow[t]{2}{*}{ Leptin males } & $\downarrow 1.7$ & $\uparrow 34.2$ & 4.7 & $p=0.001$ & $p<0.001$ & $p<0.001$ \\
\hline & $(0.3-19.6)$ & $(1.7-90.9)$ & $(0.3-19.1)$ & & & \\
\hline Resistin (ng/ml) & 10.9 & 9.9 & 10.8 & n.s. & n.s. & n.s. \\
\hline $8.3 / 11.1$ & $(4.2-43.5)$ & $(3.7-83.6)$ & $(5.2-24.9)$ & & & \\
\hline MCP-1 (pg/ml) & $\uparrow 127$ & $\uparrow 108$ & 43.9 & $p<0.001$ & $p<0.001$ & $p=0.047$ \\
\hline $5.1 / 11.2$ & $(22.7-451)$ & $(39.6-293)$ & $(12.1-150)$ & & & \\
\hline Active PAl-1 (ng/ml) & $\uparrow 13.2$ & $\uparrow 57.5$ & 6.0 & $p<0.001$ & $p<0.001$ & $p<0.001$ \\
\hline $17.4 / 20.0$ & $(2.4-53.2)$ & $(3.7-176.7)$ & $(2.4-31.3)$ & & & \\
\hline TNF-a(pg/ml) & $4.8(n=63)$ & 4.0 & 3.9 & n.s. & n.s. & n.s. \\
\hline $9.4 / 10.7$ & $(2.4-74.7)$ & $(2.4-26.8)$ & $(2.4-10.9)$ & & & \\
\hline IL-1a (pg/ml) & $\uparrow 52.4(n=63)$ & $\uparrow 59.4$ & 11.0 & $p<0.001$ & $p<0.001$ & n.s. \\
\hline $20.0 / 35.7$ & $(9.2-1322)$ & $(9.2-210.0)$ & $(9.2-168)$ & & & \\
\hline
\end{tabular}

$\downarrow \uparrow$ : Significantly elevated/lowered concentrations compared to BD.The inter- and intra-assay CVs are given below the corresponding parameters.

\section{Results}

Baseline characteristics of the study participants

Morbidly obese patients (24 female, 13 male) had a median age of 45 years (range: 17 - 59) and a median BMI of $52.0 \mathrm{~kg} / \mathrm{m}^{2}$ (range: 33.5 - 78.0). The healthy BD (30 female, 30 male) had a median age of 45 years (range: 19 - 71 years). Body mass index (BMI) was not ascertained in this group. The CRC subgroup (25 female, 42 male) included patients with colon cancer (36) and rectal cancer (31). Median age of CRC patients was 66 years (range: 28 - 91 years), median BMI was $27.1 \mathrm{~kg} / \mathrm{m}^{2}$ (range: 18.9 - 38.3). Rectal cancer was staged as stage I in 11, stage II in 3, stage III in 11, and stage IV in 6 patients. Colon cancer was staged as stage I in 8 , stage II in 12 , stage III in 12 , and stage IV in 4 patients [22]. The BMIs of $\mathrm{MO}$ patients were significantly higher compared to those of CRC patients ( $<<0.01$; WMU-T-Test). Gender-specific anthropometric data of all three groups are listed in Table 2.

Adipocytokine concentrations were clearly changed in $\mathrm{CRC}$ and $\mathrm{MO}$ patients compared to healthy BD. For a better overview, plasma concentrations of adiponectin, resistin, leptin, active PAI-1, MCP-1, IL- $1 \alpha$, and TNF- $\alpha$ and corresponding significant changes are shown in
Table 1. A gender-specific difference was seen in the values of adiponectin and leptin. In females, adiponectin and leptin values were elevated compared to males. Resistin, active PAI- 1, MCP-1, IL- $1 \alpha$, and TNF- $\alpha$ showed no gender-specific differences.

\section{Adipokines (adiponectin, resistin and leptin)}

There was no significant gender-specific difference in adiponectin concentrations in the CRC group compared to the $\mathrm{BD}$ group, but, as expected, adiponectin was lowered in the MO group ( $\mathrm{p}<0.001$ females and males). However, significant differences in the plasma leptin concentrations were detected in CRC patients compared to MO patients. Leptin concentrations were significantly lowered in CRC patients and significantly elevated in the MO compared to the BD group ( $\mathrm{p} \leq 0.01$; Table 1$)$. Resistin concentrations showed no differences between the groups.

Plasma leptin concentrations in male patients with colon carcinoma tended to be elevated compared to male patients with rectal carcinoma (median leptin: $1.7 \mathrm{ng} / \mathrm{ml}$; range: 0.3 - $19.6 \mathrm{ng} / \mathrm{ml}$ vs. $0.9 \mathrm{ng} / \mathrm{ml}$; range: $0.3-6.7 \mathrm{ng} / \mathrm{ml}$; $\mathrm{p}=0.070)$. Females with colon/rectal cancer had comparable leptin concentrations $(6.3 \mathrm{ng} / \mathrm{ml}$ vs. $9.2 \mathrm{ng} / \mathrm{ml} ; \mathrm{p}=0.591$; 
Table 2 Gender-specific anthropometric data (age and BMI) of patients with colorectal cancer (CRC), morbid obesity (MO) and healthy blood donors (BD)

\begin{tabular}{|c|c|c|}
\hline & Age [years] (median; range) & BMI $\left[\mathrm{kg} / \mathrm{m}^{2}\right]$ (median; range) \\
\hline CRC $(n=67)$ & 66.0 years $(28-91)$ & $27.1 \mathrm{~kg} / \mathrm{m}^{2}(18.9-38.3)$ \\
\hline Female patients $(n=25)$ & 66.0 years $(28-91)$ & $26.4 \mathrm{~kg} / \mathrm{m}^{2}(18.9-35.5)$ \\
\hline Male patients $(n=42)$ & 65.5 years $(37-90)$ & $27.2 \mathrm{~kg} / \mathrm{m}^{2}(20.6-38.3)$ \\
\hline Female rectal tumor patients $(\mathrm{n}=12)$ & 64.5 years $(41-84)$ & $27.6 \mathrm{~kg} / \mathrm{m}^{2}(18.9-35.5)$ \\
\hline Male rectal tumor patients $(n=19)$ & 64.0 years $(37-90)$ & $27.2 \mathrm{~kg} / \mathrm{m}^{2}(20.6-38.3)$ \\
\hline Female colon tumor patients ( $n=13$ ) & 66.0 years $(28-91)$ & $26.3 \mathrm{~kg} / \mathrm{m}^{2}(22.0-32.2)$ \\
\hline Male colon tumor patients $(n=23)$ & 67.0 years $(46-90)$ & $26.8 \mathrm{~kg} / \mathrm{m}^{2}(21.6-36.3)$ \\
\hline $\mathrm{MO}(\mathrm{n}=37)$ & 45.0 years $(17-59)$ & $52.0 \mathrm{~kg} / \mathrm{m}^{2}(33.5-78.0)$ \\
\hline Female patients $(n=24)$ & 46.5 years $(23-59)$ & $52.4 \mathrm{~kg} / \mathrm{m}^{2}(35.0-78.0)$ \\
\hline Male patients $(n=13)$ & 42.0 years $(17-59)$ & $49.1 \mathrm{~kg} / \mathrm{m}^{2}(33.5-70.4)$ \\
\hline$B D(n=60)$ & 45.0 years $(19-71)$ & Not ascertained \\
\hline Female control $(n=30)$ & 44.0 years $(19-60)$ & Not ascertained \\
\hline Male control $(n=30)$ & 46.0 years $(19-71)$ & Not ascertained \\
\hline
\end{tabular}

Figure 1). Adiponectin concentrations in females and males showed no difference in rectal and colon cancer groups (female rectal: $22.5 \mu \mathrm{g} / \mathrm{ml}$; female colon: $21.9 \mu \mathrm{g} / \mathrm{ml}$; male rectal: $13.9 \mu \mathrm{g} / \mathrm{ml}$; male colon $15.9 \mu \mathrm{g} / \mathrm{ml}$ ). In all four subgroups the BMI was not significantly different (female colon/rectal: $26.4 \mathrm{~kg} / \mathrm{m}^{2}$ vs. $27.6 \mathrm{~kg} / \mathrm{m}^{2}$; male colon/rectal: $27.0 \mathrm{~kg} / \mathrm{m}^{2}$ vs. $27.9 \mathrm{~kg} / \mathrm{m}^{2}$ ). There was no significant difference in resistin concentrations among all patient groups.

\section{Correlation of adipokines in colon cancer and rectal cancer patients with tumor size based on T-staging and tumor grading}

In patients suffering from rectal carcinoma, resistin correlates positively with tumor size based on T-staging [23] $(\mathrm{r}=0.49 ; \mathrm{p}<0.01)$ and tumor grading $(\mathrm{r}=0.39 ; \mathrm{p}=0.02)$. If focused solely on males, this trend was even stronger (correlation of resistin with T-staging in males: $\mathrm{r}=0.70 ; \mathrm{p}<0.01$; correlation of resistin with tumor grading in males: $\mathrm{r}=0.56 ; \mathrm{p}<0.01)$. This effect was not seen in the female subgroup (correlation of resistin with T-staging in females: $\mathrm{r}=0.07 ; \mathrm{p}=0.41$; correlation of resistin with tumor grading in females: $\mathrm{r}=0.13 ; \mathrm{p}=0.34$ ). However, after multivariate logistic regression with adjustment for age and gender there was no significant correlation (Table 3 ). Possibly the loss of significance could be due to the limited size of subgroups. In patients suffering from colon cancer, there was no correlation of resistin concentrations with tumor size based on T-staging and tumor grading. Plasma adiponectin and leptin concentrations showed no correlation with tumor size or tumor grading in colon or rectal cancer.

Monocyte chemotactic protein-1, active PAI-1, TNF-a, IL-1a Monocyte chemotactic protein-1, active PAI-1, and IL$1 \alpha$ were significantly elevated in CRC and MO patients compared to $\mathrm{BD}$ controls whereas no significant changes in TNF- $\alpha$ were detected. However, it is striking that the plasma concentrations in both $\mathrm{MO}$ and CRC patients are changed in the same direction. Tumor necrosis factor- $\alpha($ TNF- $\alpha)$ and IL- $1 \alpha$ plasma concentrations are comparable in $\mathrm{MO}$ and CRC patients. In contrast, active PAI-1 was higher in MO than CRC patients, and MCP-1 was higher in CRC than MO patients.

\section{Discussion}

The aim of this study was to demonstrate similarities in the cytokine/chemokine profile of colorectal cancer patients and morbidly obese since obesity is linked to an increased risk of cancer [24] possibly due to adipose tissue dysfunction accompanied with alterations in the release of adipocytokines. We found increased circulating concentrations of MCP-1, PAI-1, and IL-1 $\alpha$ in both CRC and $\mathrm{MO}$ patients, while resistin and TNF- $\alpha$ were similarly expressed in $\mathrm{MO}$ and $\mathrm{CRC}$ patients. Adiponectin concentrations were lowered only in $\mathrm{MO}$ patients, whereas leptin concentrations were lowered in CRC patients.

Adipokines, in particular leptin and adiponectin, have attracted much attention because of their potential role in the development and progression of various obesityrelated malignancies [25,26]. We found lowered leptin concentrations in CRC patients in agreement with other studies [27]. Sălăgeanu and co-workers even report a negative correlation between leptin and T-staging [19]. Interestingly, we found a significant difference in leptin concentrations of male patients with colon carcinoma vs. patients with rectal carcinoma. This difference was not seen in female patients. Since both patient groups have approximately the same BMI, this difference cannot be explained by an obesity-related leptin elevation alone. 


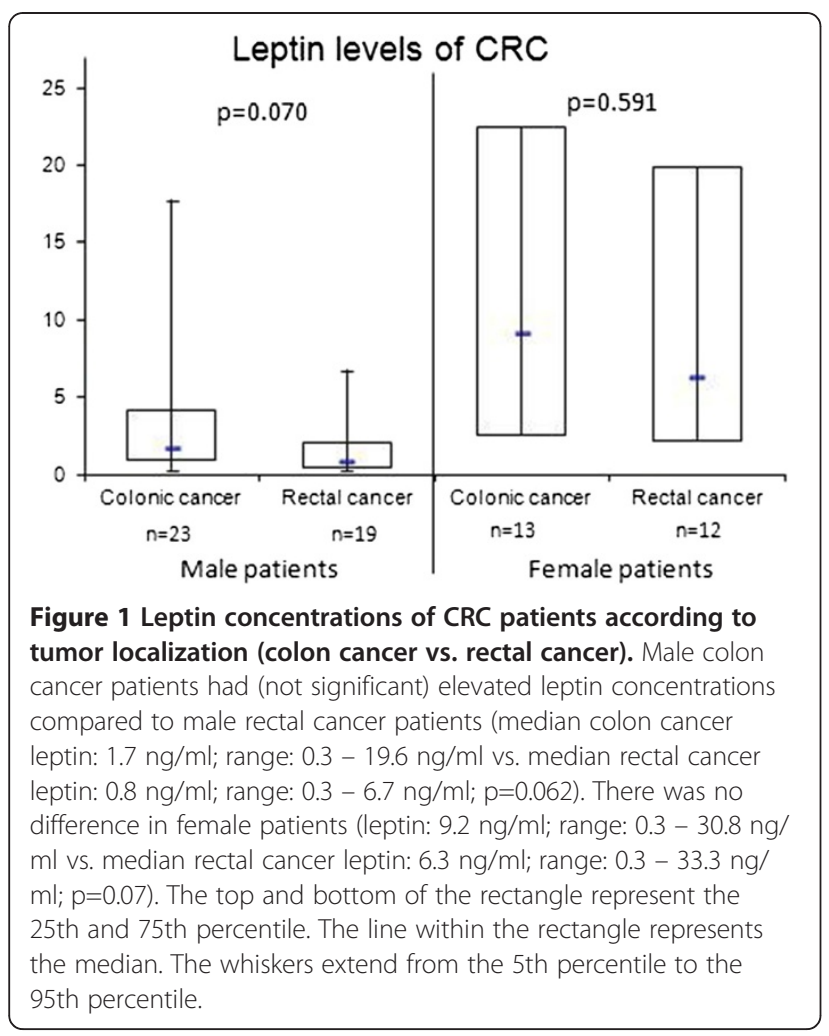

A similar association of colon cancer and elevated leptin concentrations in males was observed by Stattin and coworkers [28]. Gender-specific concentrations were significantly lowered in patients with CRC compared to the control group. As suspected, leptin concentrations showed a positive correlation to patients' BMI.

Adiponectin may be a molecular marker for obesity and CRC but evidence from large prospective studies is limited [29]. Adiponectin is decreased in the obese and is supposed to exert an anti-inflammatory and anticancerous activity. Its absence is related to several obesity-related malignancies including colorectal cancer [30]. In several further studies, low plasma adiponectin concentrations were an independent risk factor for colorectal cancer and its precursory adenoma [31-33]. However, we report, as do others [34,35], no association between plasma adiponectin concentration and CRC. The association between adiponectin concentrations and the risk of colorectal cancer still remains controversial, especially as there are different fractions of adiponectin (total/high molecular weight/non-high molecular weight adiponectin) with different hypothesized biological activities [29].

Resistin, a protein with proinflammatory properties, is mainly expressed from macrophages rather than adipocytes [36]. We observed similar resistin concentrations in both CRC and MO. Resistin correlates positively with tumor size based on T-staging and tumor grading. However, no significant results after adjustment for age and gender could be observed by multivariate logistic regression due to the small number of cases. Further studies found resistin being significantly elevated in cancer patients and in several studies stage progression significantly correlates with resistin concentrations [37,38]. We found this trend to be stronger in males and only in rectal cancer and not in colon cancer. In most other studies, there is neither a gender specific differentiation nor one between colon and rectal cancer $[27,38]$.

Tumor necrosis factor- $\alpha$ (TNF- $\alpha)$ is a key cytokine, not secreted by adipocytes but produced by both macrophages and malignant cells [39,40]. Expression and secretion of TNF- $\alpha$ increase with obesity and correlate positively with body mass index [41]. Several studies suggest that TNF- $\alpha$ is involved in obesity-related insulin resistance and that TNF- $\alpha$ is one of the most important mediators of inflammation [42]. We found a slight but not significant elevation of TNF- $\alpha$ in CRC patients compared to $\mathrm{MO}$ and $\mathrm{BD}$.

Plasminogen activator inhibitor-1 (PAI-1), a physiological inhibitor of urokinase-type and tissue-type plasminogen activator, is an integral part of the fibrinolytic system and contributes to the process of tumor invasion and metastasis due to degrading of the cellular matrix $[43,44]$. It was shown that plasma PAI-1 concentrations correlated with metastatic disease in CRC patients [45] and with the outcome of rectal cancer [46]. We also found significantly elevated PAI-1 concentrations in CRC patients as well as in MO compared to BD as control group.

Monocyte chemotactic protein-1 (MCP-1) is a chemokine that accumulates and influences tumor associated macrophages. This accumulation of macrophages seems

Table 3 Correlation of resistin concentrations in rectal tumor patients with tumor size based on T-staging and tumor grading - multivariate logistic regression with adjustment for age and gender

\begin{tabular}{lllll}
\hline Variable & Parameter & p-value & 95\%-Confidence interval (lower limit) & 95\%-Confidence interval (upper limit) \\
\hline Intercept & 2.24 & 0.59 & -6.28 & 10.76 \\
Age & 0.09 & 0.13 & -0.03 & 0.22 \\
Gender & 1.93 & 0.22 & -1.24 & 5.10 \\
Grade & 1.06 & 0.67 & -4.04 & 6.15 \\
Stage & 2.11 & 0.19 & -1.09 & 5.31 \\
\hline
\end{tabular}


to have an impact on cancer pathogenesis by influencing either growth promotion or growth inhibition depending upon the particular setting [47]. The presence of the infiltrating macrophages has been shown to correlate with cancer metastasis and poor prognosis in a variety of human carcinomas [48]. The expression of MCP-1 has been reported in several tumors including human colorectal cancer $[49,50]$. We found elevated concentrations in MO as well as in CRC patients.

Interleukin-1 is a major mediator of inflammation and is known to be up-regulated in many tumor types and has been implicated as a factor in tumor progression [51]. Interleukin-1 consists of two molecular species, IL- $1 \alpha$ and IL-1 $\beta$, both of which exert similar biological functions through the IL-1 type I receptor [52]. As in cancer, elevated IL-1 concentrations are reported in obesity [17]. Since macrophages accumulate in both tissues, in adipose tissue in MO and cancer tissue in CRC patients, elevated IL- $1 \alpha$ concentrations are unsurprising in both our groups.

Examining these cytokines, it is striking that plasma concentrations of $\mathrm{MO}$ and $\mathrm{CRC}$ are changed in the same direction. The amplitude of change of $\mathrm{MO}$ and CRC to $\mathrm{BD}$ is comparable in TNF- $\alpha$ and IL- $1 \alpha$ plasma concentrations. Active PAI-1 is proportionally more elevated in MO compared to CRC. Monocyte chemotactic protein1 , however, is proportionally more elevated in CRC compared to MO. This could be explained by the fact that PAI-1 is not only produced by the visceral adipose tissue (increased in the morbidly obese) but also by steatotic liver tissue in morbidly obese patients [53,54]. Monocyte chemotactic protein-1 is produced by cancer cells and multiple different host cells within the tumor microenvironment and serves as one of the key mediators of interactions between tumor and host cells [55]. Similar cytokine/chemokines/PAI-1 profile in $\mathrm{MO}$ and CRC patients reflects the obesity and tumor associated chronic inflammation. However, the specific influence of adipokines on tumor development and progression is still not fully understood and has to be addressed.

Our study has several strengths and limitations. All patients were recruited and operated on in the same hospital. Blood samples of all three groups were collected via the same protocol, were simultaneously stored, and processed with the same assay. Patients of the MO group were not only overweight, but truly morbidly obese (median BMI of MO patients: $52.0 \mathrm{~kg} / \mathrm{m}^{2}$ ). In the absence of standard values for many adipocytokines we provide a profile for the three different groups.

The main limitation of our study is the missing BMI of the BD group due to the fact that in general body weight and height are not routinely measured in the Institute of Clinical Transfusion Medicine and Immunogenetics. This obviously affects the interpretation of the results. Further limitations are the small sample size and the associated lack of significance in statistical analysis of the data and the lack of correlation of resistin levels with tumor size based on T-staging and tumor grading in patients suffering from colon cancer. Further, no information was collected regarding a screening colonoscopy for colorectal cancer in the $\mathrm{BD}$ group.

\section{Conclusion}

The aim of this study was to demonstrate similarities in the cytokine/chemokine profile of colorectal cancer patients and morbidly obese since obesity is linked to an increased risk of cancer, possibly due to adipose tissue dysfunction. We demonstrated similarities in the cytokine/chemokine profile of CRC and MO patients. We found significantly lowered leptin concentrations (gender dependent) in the carcinoma group compared to BD. In male patients with colon carcinoma, we report elevated leptin concentrations compared to leptin concentrations in rectal tumor patients. Further, we found a positive correlation of resistin and tumor size based on T-staging in CRC males. Similarities in the cytokine/chemokine profile of colorectal cancer patients and the morbidly obese indicate that both have chronic lowgrade inflammation as part of their etiology. Future studies are warranted to confirm these results and to elucidate the underlying mechanisms.

\section{Abbreviations}

BD: Blood donors; CRC: Colorectal carcinoma; CV\%: Coefficient of variation; IL-1: Interleukin-1; MCP-1: Monocyte chemotactic protein-1; MO: Morbidly obese patients; PAI-1: Active plasminogen activator inhibitor-1; TNF-a: Tumor necrosis factor (TNF)-a.

\section{Competing interests}

All authors declare that they have no competing interests.

\section{Authors' contributions}

All the authors have contributed substantially to the submitted work and have read and revised the paper and approved the final version. In particular $\mathrm{AH}, \mathrm{UK}$ and $\mathrm{AMW}$ participated in the design of the study, data acquisition, analysis and drafting of the manuscript. JF, NH and PX analyzed the data and provided the literature research. AH, MT and UK analyzed the plasma levels. DHB initialized the work, provided laboratory results and gave approval for submission. HS provided data of blood donors. AMW and UK obtained ethical approval.

\section{Authors' information}

Anna Maria Wolf and Uwe Knippschild shared senior authorship.

\section{Author details}

'Department of General and Visceral Surgery, University Hospital of UIm, Albert-Einstein-Allee 23, 89081, Ulm, Germany. ${ }^{2} \mathrm{NMI}$ at the University of Tuebingen, Markwiesenstr. 55, 72770, Reutlingen, Germany. Institute of Clinical Tranfusion Medicine and Immunogenetics, Helmholtzstr. 10, 89081, Ulm, Germany.

Received: 1 April 2012 Accepted: 20 November 2012 Published: 23 November 2012 


\section{References}

1. WHO: Obesity: preventing and managing the global epidemic. Report of a WHO consultation. World Health Organ Tech Rep Ser 2000, 894(i-xii):1-253.

2. Calle EE, Thun MJ: Obesity and cancer. Oncogene 2004, 23:6365-6378.

3. Wolk A, Gridley G, Svensson M, Nyren O, McLaughlin JK, Fraumeni JF, Adam $\mathrm{HO}$ : A prospective study of obesity and cancer risk (Sweden). Cancer Causes Control 2001, 12:13-21.

4. Calle EE, Kaaks R: Overweight, obesity and cancer: epidemiological evidence and proposed mechanisms. Nat Rev Cancer 2004, 4:579-591.

5. Calle EE, Rodriguez C, Walker-Thurmond K, Thun MJ: Overweight, obesity, and mortality from cancer in a prospectively studied cohort of U.S. adults. N Engl J Med 2003, 348:1625-1638.

6. Renehan AG, Tyson M, Egger M, Heller RF, Zwahlen M: Body-mass index and incidence of cancer: a systematic review and meta-analysis of prospective observational studies. Lancet 2008, 371:569-578.

7. Siddiqui AA: Metabolic syndrome and its association with colorectal cancer: a review. Am J Med Sci 2010, 341:227-231.

8. Ford ES: Body mass index and colon cancer in a national sample of adult U.S. men and women. Am J Epidemio/ 1999, 150:390-398.

9. Maclnnis RJ, English DR, Hopper JL, Gertig DM, Haydon AM, Giles GG: Body size and composition and colon cancer risk in women. Int J Cancer 2006, 118:1496-1500.

10. Larsson SC, Wolk A: Obesity and colon and rectal cancer risk: a meta-analysis of prospective studies. Am J Clin Nutr 2007, 86:556-565.

11. Siegel EM, Ulrich CM, Poole EM, Holmes RS, Jacobsen PB, Shibata D: The effects of obesity and obesity-related conditions on colorectal cancer prognosis. Cancer Control 2010, 17:52-57.

12. VanKruijsdijk RC, van der Wall E, Visseren FL: Obesity and cancer: the role of dysfunctional adipose tissue. Cancer Epidemiol Biomarkers Prev 2009, $18: 2569-2578$

13. Phillips LK, Prins JB: The link between abdominal obesity and the metabolic syndrome. CurrHypertens Rep 2008, 10:156-164.

14. Dinarello CA: Proinflammatory cytokines. Chest 2000, 118:503-508.

15. Yamaji T, Iwasaki M, Sasazuki S, Tsugane S: Interaction between adiponectin and leptin influences the risk of colorectal adenoma. Cancer Res 2010, 70:5430-5437.

16. Guadagni F, Roselli M, Martini F, Spila A, Riondino S, D'Alessandro R, Del Monte G, Formica V, Laudisi A, Portarena I, Palmirotta R, Ferroni P: Prognostic significance of serum adipokine levels in colorectal cancer patients. Anticancer Res 2009, 29:3321-3327.

17. Osborn O, Gram H, Zorrilla EP, Conti B, Bartfai T: Insights into the roles of the inflammatory mediators IL-1, IL-18 and PGE2 in obesity and insulin resistance. Swiss Med Wkly 2008, 138:665-673.

18. Mantovani A, Bottazzi B, Colotta F, Sozzani S, Ruco L: The origin and function of tumor-associated macrophages. Immunol Today 1992, 13:265-270.

19. Sălăgeanu A, Tucureanu C, Lerescu L, Caraş I, Pitica R, Gangurà G, Costea R, Neagu S: Serum levels of adipokines resistin and leptin in patients with colon cancer. J Med Life 2010, 3:416-420.

20. Housa D, Housova J, Vernerova Z, Haluzik M: Adipocytokines and cancer. Physiol Res 2006, 55:233-244.

21. Lang K, Ratke J: Leptin and adiponectin: new players in the field of tumor cell and leukocyte migration. Cell Commun Signal 2009, 7:27.

22. Edge SE, Byrd DR, Carducci MA, Compton CC: AJCC cancer staging manual. 7th edition. New York, NY: Springer; 2010.

23. Sobin LH, Gospodarowicz MK, Wittekind C: UICC: TNM classification of malignant tumors. 7th edition. Oxford: Wiley-Blackwell; 2009.

24. Harvey AE, Lashinger LM, Hursting SD: The growing challenge of obesity and cancer: an inflammatory issue. Ann N Y Acad Sci 2011, 1229:45-52.

25. Kelesidis I, Kelesidis T, Mantzoros CS: Adiponectin and cancer: a systematic review. Br J Cancer 2006, 94:1221-1225.

26. Stattin P, Lukanova A, Biessy C, Söderberg S, Palmqvist R, Kaaks $R$, Olsson T, Jellum E: Obesity and colon cancer: does leptin provide a link? Int J Cancer 2004, 109:149-152.

27. Kumor A, Daniel P, Pietruczuk M, Małecka-Panas E: Serum leptin, adiponectin, and resistin concentration in colorectal adenoma and carcinoma (CC) patients. Int J Colorectal Dis 2009, 24:275-281.

28. Stattin P, Palmqvist R, Söderberg S, Biessy C, Ardnor B, Hallmans G, Kaaks R, Olsson T: Plasma leptin and colorectal cancer risk: a prospective study in Northern Sweden. Oncol Rep 2003, 10:2015-2021.
29. Aleksandrova $K$, Boeing $H$, Jenab M, Bueno-de-Mesquita $H B$, Jansen $E$, van Duijnhoven FJ, Fedirko V, Rinaldi S, Romieu I, Riboli E, Romaguera D, Westphal S, Overvad K, Tjønneland A, Boutron-Ruault MC, Clavel-Chapelon F, Kaaks R, Lukanova A, Trichopoulou A, Lagiou P, Trichopoulos D, Agnoli C, Mattiello A, Saieva C, Vineis P, Tumino R, Peeters PH, Argüelles M, Bonet $C$, Sánchez MJ, Dorronsoro M, Huerta JM, Barricarte A, Palmqvist R, Hallmans G, Khaw KT, Wareham N, Allen NE, Crowe FL, Pischon T: Total and highmolecular weight adiponectin and risk of colorectal cancer: the European prospective investigation into cancer and nutrition study. Carcinogenesis 2012, 33:1-8.

30. Saxena A, Chumanevich A, Fletcher E, Larsen B, Lattwein K, Kaur K, Fayad R: Adiponectin deficiency: role in chronic inflammation induced colon cancer. BiochimBiophysActa 2012, 1822:527-536.

31. Wei EK, Giovannucci E, Fuchs CS, Willett WC, Mantzoros CS: Low plasma adiponectin levels and risk of colorectal cancer in men: a prospective study. J Natl Cancer Inst 2005, 97:1688-1694.

32. Otake S, Takeda H, Suzuki Y, Fukui T, Watanabe S, Ishihama K, Saito T, Togashi H, Nakamura T, Matsuzawa Y, Kawata S: Association of visceral fat accumulation and plasma adiponectin with colorectal adenoma: evidence for participation of insulin resistance. Clin Cancer Res 2005, 11:3642-3646

33. Ho GY, Wang T, Gunter MJ, Strickler HD, Cushman M, Kaplan RC, Wassertheil-Smoller S, Xue X, Rajpathak SN, Chlebowski RT, Vitolins MZ, Scherer PE, Rohan TE: Adipokines linking obesity with colorectal cancer risk in postmenopausal women. Cancer Res 2012, 72:3029-3037.

34. Chronis A, Thomopoulos K, Sapountzis A, Triantos C, Kalafateli M, Kalofonos C, Nikolopoulou V: Adiposity factors are not related to the presence of colorectal adenomas. ClinExpGastroenterol. 2011, 4:257-261.

35. Landskroner-Eiger S, Qian B, Muise ES, Nawrocki AR, Berger JP, Fine EJ, Koba W, Deng Y, Pollard JW, Scherer PE: Proangiogenic contribution of adiponectin toward mammary tumor growth in vivo. Clin Cancer Res 2009, 15:3265-3276.

36. Patel L, Buckels AC, Kinghorn IJ, Murdock PR, Holbrook JD, Plumpton C, Macphee $\mathrm{CH}$, Smith SA: Resistin is expressed in human macrophages and directly regulated by PPAR gamma activators. BiochemBiophys Res Commun 2003, 300:472-476.

37. Nakajima TE, Yamada Y, Hamano T, Furuta K, Matsuda T, Fujita S, Kato K, Hamaguchi T, Shimada Y: Adipocytokines as new promising markers of colorectal tumors: adiponectin for colorectal adenoma, and resistin and visfatin for colorectal cancer. Cancer Sci 2010, 101:1286-1291.

38. Gonullu G, Kahraman H, Bedir A, Bektas A, Yücel I: Association between adiponectin, resistin, insulin resistance, and colorectal tumors. Int $J$ Colorectal Dis 2010, 25:205-212.

39. Cox GW, Melillo G, Chattopadhyay U, Mullet D, Fertel RH, Varesio L: Tumor necrosis factor-a-dependent production of reactive nitrogen intermediates mediates IFN- $\gamma$ plus IL-2-induced murine macrophage tumoricidal activity. J Immunol 1992, 149:3290-3296.

40. Mohamed-Ali V, Goodrick S, Rawesh A, Katz DR, Miles JM, Yudkin JS, Klein S, Coppack SW: Subcutaneous adipose tissue releases interleukin-6, but not tumor necrosis factor-alpha, in vivo. J ClinEndocrinolMetab 1997, 82:4196-4200

41. Sethi JK, Hotamisligil GS: The role of TNF alpha in adipocyte metabolism. Semin Cell DevBiol 1999, 10:19-29.

42. Kern PA, Ranganathan S, Li C, Wood L, Ranganathan G: Adipose tissue tumor necrosis factor and interleukin-6 expression in human obesity and insulin resistance. Am J PhysiolEndocrinolMetab 2001, 280:E745-E751.

43. Sternlicht MD, Dunning AM, Moore DH, Pharoah PD, Ginzinger DG, Chin K, Gray JW, Waldman FM, Ponder BA, Werb Z: Prognostic value of PAl1 in invasive breast cancer: evidence that tumor-specific factors Are more important than genetic variation in regulating PAl1 expression cancer. Epidemiol Biomarkers Prev 2006, 15:2107-2114.

44. Nielsen HJ, Pappot H, Christensen IJ, Brünner N, Thorlacius-Ussing O, Moesgaard F, Danø K, Grøndahl-Hansen J: Association between plasma concentrations of plasminogen activator inhibitor-1 and survival in patients with colorectal cancer. BMJ 1998, 316:829-830.

45. Langenskiöld M, Holmdahl L, Angenete E, Falk P, Nordgren S, Ivarsson ML: Differential prognostic impact of UPA and PAI-1 in colon and rectal cancer. TumourBiol 2009, 30:210-220.

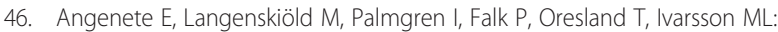
UPA and PAI-1 in rectal cancer-relationship to radiotherapy and clinical outcome. J Surg Res 2009, 153:46-53. 
47. Deshmane SL, Kremlev S, Amini S, Sawaya BE: Monocyte chemoattractant protein-1 (MCP-1): an overview. J Interferon Cytokine Res 2009, 29:313-326.

48. Siveen $\mathrm{KS}$, Kuttan G: Role of macrophages in tumour progression. Immunollett 2009, 123:97-102.

49. Koide N, Nishio A, Sato T, Sugiyama A, Miyagawa S: Significance of macrophage chemoattractant protein-1 expression and macrophage infiltration in squamous cell carcinoma of the esophagus. Am J Gastroenterol 2004, 99:1667-1674

50. Bailey C, Negus R, Morris A, Ziprin P, Goldin R, Allavena P, Peck D, Darzi A: Chemokine expression is associated with the accumulation of tumour associated macrophages (TAMs) and progression in human colorectal cancer. ClinExp Metastasis 2007, 24:121-130.

51. Lewis AM, Varghese $\mathrm{S}, \mathrm{Xu} H$, Alexander HR: Interleukin-1 and cancer progression: the emerging role of interleukin-1 receptor antagonist as a novel therapeutic agent in cancer treatment. J Trans/ Med 2006, 4:48.

52. Matsuki T, Horai R, Sudo K, Iwakura Y: IL-1 plays an important role in lipid metabolism by regulating insulin levels under physiological conditions. J Exp Med 2003, 198:877-888.

53. Mertens I, Van Gaal LF: Visceral fat as a determinant of fibrinolysis and hemostasis. SeminVasc Med 2005, 5:48-55.

54. Alessi MC, Bastelica D, Mavri A, Morange P, Berthet B, Grino M, Juhan-Vague I: Plasma PAl-1 levels are more strongly related to liver steatosis than to adipose tissue accumulation. ArteriosclerThrombVascBiol 2003, 23:1262-1268.

55. Zhang J, Patel L, Pienta KJ: Targeting chemokine (C-C motif) ligand 2 (CCL2) as an example of translation of cancer molecular biology to the clinic. ProgMolBiolTrans/ Sci. 2010, 95:31-53.

doi:10.1186/1471-2407-12-545

Cite this article as: Hillenbrand et al: Changed adipocytokine concentrations in colorectal tumor patients and morbidly obese patients compared to healthy controls. BMC Cancer 2012 12:545.

\section{Submit your next manuscript to BioMed Central and take full advantage of:}

- Convenient online submission

- Thorough peer review

- No space constraints or color figure charges

- Immediate publication on acceptance

- Inclusion in PubMed, CAS, Scopus and Google Scholar

- Research which is freely available for redistribution 